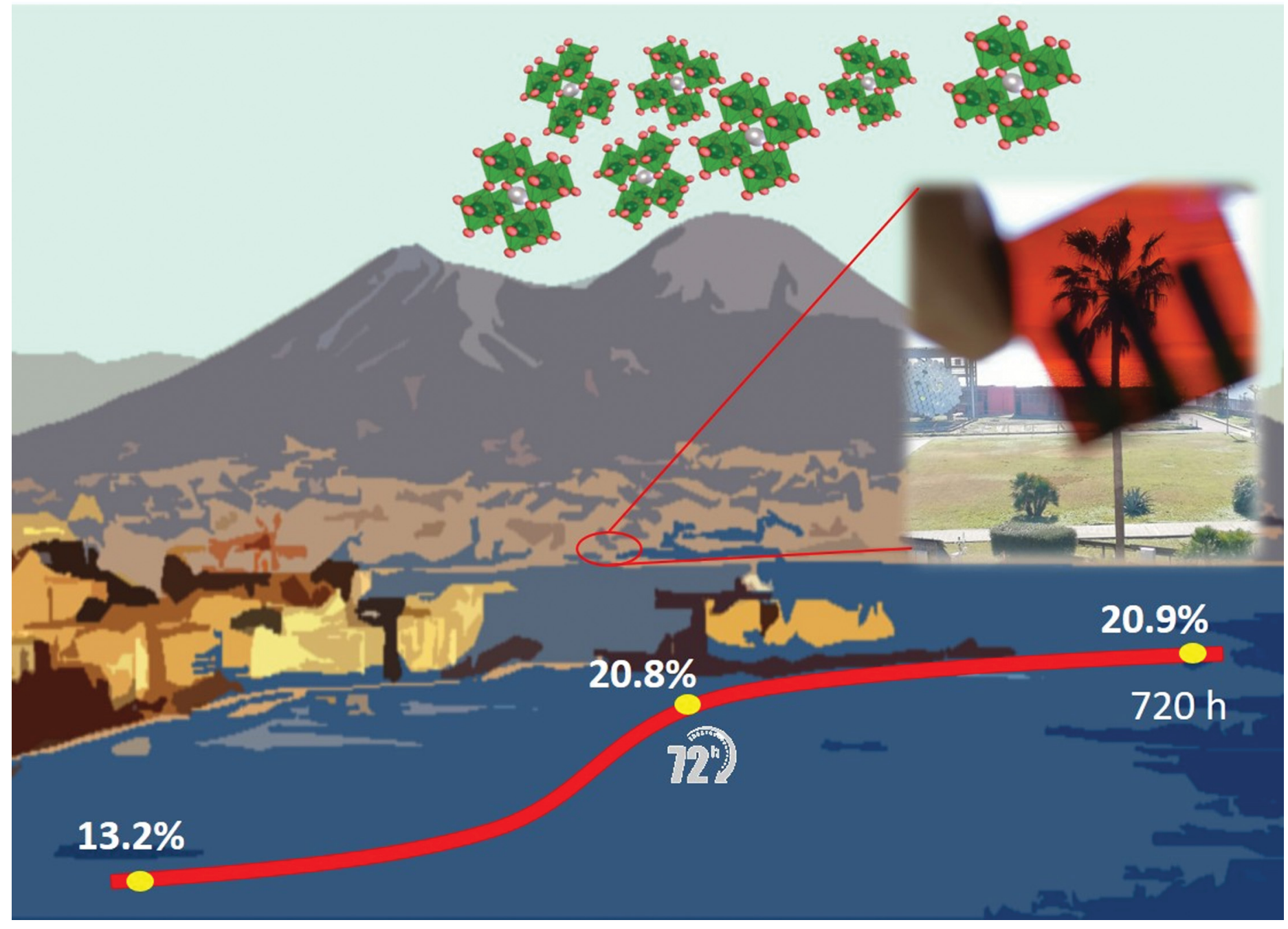

Innovative and Photovoltaic Devices Laboratory, situated in Portici - ITALY, is an ENEA research group focused on the development of materials and device architecture for high efficient solar cells, as perovskite/silicon tandem solar cells.

The effect of storage cycle on improvement in the photovoltaic parameters of planar triple cation perovskite solar cells

Un-encapsulated planar triple cation solar cells were characterized over time after storage in moderate humid air/low vacuum environment. A rise of efficiency from $13.2 \%$ to $20.8 \%$ after $72 \mathrm{~h}$ was recorded and, after $720 \mathrm{~h}$ from fabrication day and low vacuum storage, a slight efficiency increase to $20.9 \%$ was further reached. An enhancement of all PV parameters and hysteresis-free respect to pristine cells were shown. The storage cycle could be a route to improve the performance of pristine perovskite solar cells and to proceed with encapsulation.
As featured in:

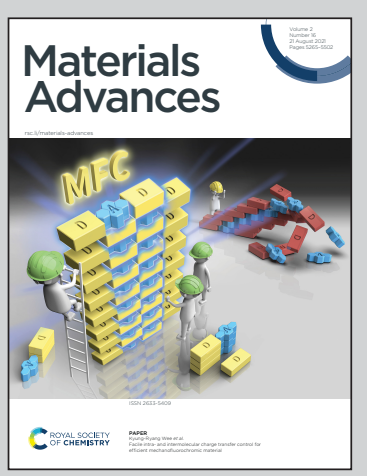

See Vera La Ferrara et al., Mater. Adv., 2021, 2, 5396. 
Check for updates

Cite this: Mater. Adv., 2021, 2, 5396

Received 15th April 2021,

Accepted 21st June 2021

DOI: $10.1039 / \mathrm{d} 1 \mathrm{ma} 00345 \mathrm{c}$

rsc.li/materials-advances

\section{The effect of storage cycle on improvement in the photovoltaic parameters of planar triple cation perovskite solar cells $\dagger$}

\begin{abstract}
Vera La Ferrara, (D) * Antonella De Maria, Gabriella Rametta (D) and Paola Delli Veneri
One of the important challenges in the field of perovskite solar cells is to investigate the competitive mechanisms of humidity and oxygen which improve the efficiency of cells at moderate humidity and cause the degradation of perovskites at high levels of moisture. We found that when an un-encapsulated standard planar architecture, glass/ITO/SnO $2 /$ triple cation perovskite/Spiro-OMeTAD/Au, was realized, exposure to moderate humid air was always needed for proper functioning. We investigated the fabrication and storage procedures of thin $(\sim 320 \mathrm{~nm})$ triple cation perovskite solar cells showing, for the first time, to the best of our knowledge, a remarkable enhancement of all photovoltaic parameters compared to those of pristine cells (with the fill factor exceeding $80 \%$, a short circuit current density of about $24 \mathrm{~mA} \mathrm{~cm}^{-2}$ and an open circuit voltage of $1121 \mathrm{mV}$, for champion devices) and, particularly, an impressive increase of power conversion efficiency (PCE) from $13.2 \%$ to $20.8 \%$ after $72 \mathrm{~h}$ of storage in air with moderate humidity. A slight PCE increase to $20.9 \%$ was also achieved after subsequent low vacuum storage and after $720 \mathrm{~h}$ from the fabrication day. Moreover, devices exhibiting hysteresis-free behavior after storage were characterized for evaluating the mechanism of charge carrier recombination by means of dark and light current density-voltage and illumination-dependent photovoltaic parameters. The storage cycle shown in this work could be a possible route to improve the performance of pristine perovskite solar cells and consequently to proceed with encapsulation procedures.
\end{abstract}

\section{Introduction}

The most appealing features of perovskite solar cells (PSCs), such as high light absorption, excellent ambipolar charge mobility, small binding energy, high efficiency and low fabrication cost, have drawn attention from the scientific community achieving remarkable power conversion efficiency (PCE) improvements in few years, from 3.9 to $25.5 \% .^{1-4}$ Despite the strong advances in technology, there is still a number of relevant effects that are subject to ongoing investigations. These effects could include, for example, less stability against light exposure, temperature and moisture and the dependence of $J-V$ curves on the scan direction, e.g. hysteresis. ${ }^{5-11}$ Moreover, in the wide variety of perovskite chemical compositions, multi-cation perovskites have attracted increasing attention for different photovoltaic (PV) applications such as transparent windows, photodetectors, and flexible and tandem devices. ${ }^{12-17}$ In the perovskite layer, the absorption of light generates free electrons and holes whose transport is

Italian National Agency for New Technologies, Energy and Sustainable Economic Development (ENEA) - Portici Research Center, Piazzale E. Fermi, 80055 Portici (Na), Italy.E-mail: vera.laferrara@enea.it

$\dagger$ Electronic supplementary information (ESI) available. See DOI: 10.1039/d1ma00345c dependent on the device architecture, thickness and chemical composition of the perovskite absorber. PSCs generally consist of about 200-1000 nm layers of perovskites, sandwiched between two charge transporting layers, e.g. electron and hole transport materials (ETMs and HTMs, respectively). Many aspects are still under investigation to obtain high-quality perovskite solar cells. One of the desired goals is to use, for example, thin perovskite films for lowering the $\mathrm{Pb}$ content and reducing the cost, while maintaining high performances. ${ }^{16,17}$ More efforts are also devoted to investigating the ETM layer properties, together with the HTM properties, for effective carrier separation at the perovskite interface resulting in lower charge recombination at the interface contacts. One of the commonly employed ETMs is $\mathrm{TiO}_{2}$, which, together with a transparent conductive oxide (TCO) such as indium tin oxide (ITO) or fluorine-doped tin oxide (FTO), forms a photoanode in both planar and mesoscopic perovskite high efficiency solar cells. ${ }^{18-22}$ More recently, tin dioxide has been studied as an alternative to $\mathrm{TiO}_{2}$, especially for its advantage of getting deposited by low temperature processes, for facilitating also the integration of perovskite solar cells in promising monolithic tandem perovskitesilicon solar cells..$^{13,23-25}$ However, irrespective of the ETM or HTM, it is also important to reduce the defects, which are spontaneously 
and inevitably formed during the conventional device manufacturing process, both at the surface of the perovskite film and at the interfaces of the ETM and HTM. Lowering defects implies a reduction of recombination mechanisms to obtain high quality PSCs. ${ }^{26-29}$ In an ideal cell, the only recombination channel is the radiative recombination of free electrons and holes in the same layer where they are generated. In contrast, the real presence of defects, in the perovskite absorber material, inserts energy transition levels (trap states) trapping the free charges and affecting the charge transport. The most efficient strategies to compensate for these disadvantages are surface and interface passivation. A wide variety of materials, ranging from inorganic to organic molecules or even polymers, have been used as passivating layers through self-assembled monolayer deposition and self-passivation due to excess or deficiency of $\mathrm{PbI}_{2}{ }^{30-36}$ More recently, air was studied as a means of passivation. According to many authors, low levels of humidity and oxygen could actually improve the crystallinity of the perovskite layer enhancing the PV performance. Oxygen in air could act as a reactant to passivate the traps, not only under illumination but also by thermal treatment in air, and it could also act as a p-type dopant. ${ }^{37-40}$ Furthermore, it was suggested that water molecules could also be a strong n-type dopant and can interact for filling deep charge carrier traps. ${ }^{8,42-45}$ Therefore, it becomes crucial to understand the effects of humid air during fabrication and probable storage. While moderate levels of humidity would positively affect the high efficiency, at high levels of moisture or prolonged time exposure at low humidity, the formation of a hydrate phase perovskite would decrease the PCE. ${ }^{5,7-11,45,46}$ With regard to this, just recently, Cho et al. ${ }^{46}$ clarified a mechanism that increases the PCE after ambient and moderate humidity storage in an $\mathrm{n}-\mathrm{i}-\mathrm{p}$ architecture based on mesoporous perovskite solar cells, with $200 \mathrm{~nm}$ mesoporous $\mathrm{TiO}_{2}$ as the ETM and $400 \mathrm{~nm}$ capping perovskite layer. They found an increase in the PCE in a double cation perovskite, in the first $48 \mathrm{~h}$ of storage, from $17.1 \%$ to $20.4 \%$, at room temperature and moderate humidity, finding that the effect of moisture on the initial cell performance improvement was a combined result of temporal changes in both the perovskite and HTM, by showing surface passivation and changes in conductivity. Insights into the competitive mechanisms of humidity and oxygen are fundamental to improve the performance of perovskite solar cells, helping the future development of the PSC technology. ${ }^{47-49,69,75}$ In this work, we focus on the fabrication and storage procedure of thin $(\sim 320 \mathrm{~nm})$ un-encapsulated triple cation perovskite solar cells with planar architecture and consequently the influence of the related PV parameters. We show, for the first time, to the best of our knowledge, a remarkable enhancement, over time, of all PV parameters (an open circuit voltage $\left(V_{\mathrm{oc}}\right)$ of $1121 \mathrm{mV}$, a short circuit current density $\left(J_{\mathrm{sc}}\right)$ of $24.07 \mathrm{~mA} \mathrm{~cm} \mathrm{cos}^{-2}$ and a fill factor (FF) of $81.6 \%$ for champion devices) and in particular, an impressive increase in PCE (from $13.2 \%$ to $20.8 \%$ after $72 \mathrm{~h}$ of storage in humid air, and a slight increase to $20.9 \%$ after subsequent low vacuum storage and $720 \mathrm{~h}$ from the fabrication day) of PSCs completely fabricated in a $\mathrm{N}_{2}$-filled glove box (GB), stored in the dark, and exposed to humid air and low vacuum, with a relative humidity $(\mathrm{RH})$ of $(30 \pm 10) \%$. The light current density-voltage $(J-V)$ characteristics of the devices, by reverse and forward scans, were measured immediately after the fabrication process and over time, the hysteresis-free behavior of the stored samples was observed. Dark $J-V$ and illumination-dependent $V_{\text {oc }}$ and $J_{\text {sc }}$ were recorded to understand the recombination mechanism which could occur for aged devices. Scanning electron microscopy (SEM) and energy dispersive X-ray (EDX) analyses were performed to evaluate the morphological and structural differences of the devices monitored over time. Our results highlight that high performance devices can be obtained with thin triple cation perovskites fabricated completely in a $\mathrm{N}_{2}$-filled glove box, followed by humid air/vacuum storage cycles.

\section{Experimental}

\section{Materials and device characterization}

$\mathrm{SnO}_{2}$ colloid precursor (tin(Iv) oxide $15 \% \mathrm{H}_{2} \mathrm{O}$ colloidal dispersion), $\mathrm{PbI}_{2}$ ( $\geq 99.999$, ultradry) and $\mathrm{PbBr}_{2}$ (Puratronic, $\geq 99.998$ ) were obtained from Alfa Aesar. CsI ( $\geq 99.999$, anhydrous) and acetonitrile (ACN) were obtained from Acros Organics. $N, N$-dymethylformamide (DMF), dimethyl sulfoxide (DMSO), formamidinium iodide (FAI), methylammonium bromide (MaBr, $\geq 99 \%$, anhydrous), Spiro-OMeTAD, chlorobenzene (CB), 4-tert-butylpyridine (TBPy), bis(trifluoromethane)sulfonimide lithium salt (Li-TFSI), and FK 209 Co(III) TFSI salt were purchased from Merck. All the chemicals were used without further purification. We used $2 \times 2 \mathrm{~cm}^{2}$ glass/ITO substrates received from Kintec (10 $\Omega \mathrm{sq}^{-1}$ ). The scanning electron microscopy (SEM) and energy-disperse X-ray (EDX) analyses were performed using a Thermo Fisher Scientific Phenom pro X SEM, with an electron beam accelerated at $15 \mathrm{kV}$, and it was equipped with a long lifetime thermoionic source of cerium hexaboride. The cross section used to evaluate the different layers in PSCs was made using an FEI Dual Beam Quanta 200 3D apparatus, which integrates a finely focused gallium ion beam (FIB). The thickness of the different layers was also measured using a KLA Tencor profilometer. The performance of the solar cells was characterized using a solar simulator (Wacom Electric Co. Ltd, WXS 155S, L2.AM1.5G) generated with two AAA class lamps (Ha and $\mathrm{Xe}$ ) located in a non-air-conditioned laboratory. The current-voltage characteristics of the devices were obtained by applying an external potential bias to the cell by recording the generated photo-current using a Keithley (Model 2651A) high power system source meter. $J-V$ data acquisition was performed at a rate of $2 \mathrm{~V} \mathrm{~s}^{-1}$ for all the electrical measurements, both forward and reverse scans, and both pristine and stored devices. All the samples were not polarized and the first measurement was always from $1.2 \mathrm{~V}$ to $-0.1 \mathrm{~V}$ (reverse scan).

\section{Device fabrication}

The fabrication process of PSCs for triple cation perovskite was developed by different authors ${ }^{50,51}$ but the final process was often modified according to requirements. To prepare perovskite solar cells, ITO glass substrates were cleaned by sonication with 
acetone and ethanol for 15 minutes each. Then, two thin layers of $\mathrm{SnO}_{2}$, as electron transport materials, were deposited by spincoater at $6000 \mathrm{rpm}$ for $30 \mathrm{~s}$ on the ITO substrates previously treated with UV-ozone. Spin-coating deposition was made under a fume extractor system, where temperature and relative humidity were monitored but not controlled because depending on the outdoor atmospheric conditions. The $\mathrm{SnO}_{2}$ solution was prepared by diluting a commercial $\mathrm{SnO}_{2}$ colloidal dispersion with deionized water $(1: 5)$. The annealing temperature was set to $130{ }^{\circ} \mathrm{C}$ for $1 \mathrm{~h}$ on a hotplate, controlled with a thermocouple, in humid air. Substrates were again treated with UV-ozone before perovskite layer deposition. Perovskite and Spiro-OMeTAD were deposited by a spinning approach in a glove box (Jacomex) with a $\mathrm{N}_{2}$ carrier and at $\mathrm{RH}$ of less than $1 \mathrm{ppm}$. The schematic diagram of the device fabrication procedure is shown in Fig. S1 (ESI $\dagger$ ).

Two batches of PSCs were fabricated on the same day $\left(T=20{ }^{\circ} \mathrm{C}\right.$ and $\left.\mathrm{RH}=(30 \pm 10) \%\right)$ : the former batch, after the $\mathrm{SnO}_{2}$ spinning process in humid air, was inserted into a nitrogenfilled glove box for perovskite and HTM spinning deposition and subsequent thermal evaporation of gold electrical contacts (hereafter denoted as devices completed inside the GB) (Fig. S1a, ESI $\dagger$ ); the latter, after perovskite and HTM spinning deposition, was kept outside the glove box, left in humid air for $1 \mathrm{~h}$, the time needed for transferring and loading in an external evaporator, for subsequent gold evaporation (hereafter denoted as devices completed outside the GB) (Fig. S1b, $\mathrm{ESI} \dagger$ ).

The perovskite $\mathrm{Cs}_{0.05} \mathrm{FA}_{0.8} \mathrm{MA}_{0.15} \mathrm{PbI}_{2.5} \mathrm{Br}_{0.5}$ (mixed cation Cs, $\mathrm{FA}=$ formamidinium, $\mathrm{MA}=$ methylammonium, and mixed halide (I,Br)) solution was prepared by mixing $\mathrm{PbI}_{2}(1.10 \mathrm{M})$, $\mathrm{PbBr}_{2}(0.22 \mathrm{M})$, FAI (1.05 M), and MABr (0.20 M) in DMF/DMSO $(4: 1 \mathrm{v} / \mathrm{v} \%)$, and the CsI iodide solution $(1.50 \mathrm{M})$ in DMSO was added to the above solution to obtain a molar ratio of $5 \%$. The perovskite spin-coating process was set as a two-step program with 1000 and $6000 \mathrm{rpm}$ for 10 and 20 seconds, respectively. $150 \mu \mathrm{L}$ of CB was added dropwise on the substrate a few seconds before spin-coating was completed. After that, the perovskite layer was crystallized by annealing at $100{ }^{\circ} \mathrm{C}$ for 1 hour. To deposit SpiroOMeTAD, HTM solution was spun on the perovskite layer at $4000 \mathrm{rpm}$ for 30 seconds. The HTM solution consists of $73 \mathrm{mg}$ of Spiro-OMeTAD diluted in $1 \mathrm{~mL}$ of $\mathrm{CB}, 27 \mu \mathrm{L}$ of TBPy, $17 \mu \mathrm{L}$ of a
Li-TFSI solution ( $520 \mathrm{mg}$ of Li-TFSI in $1 \mathrm{~mL}$ of ACN), and $7 \mu \mathrm{L}$ of a FK 209 Co(III) TFSI (375 mg of Co-complex in $1 \mathrm{~mL}$ of ACN). Finally, devices were completed in a thermal evaporator inside or outside the glove box and $80 \mathrm{~nm} \mathrm{Au} \mathrm{back-contact} \mathrm{layer} \mathrm{was}$ evaporated on the Spiro-OMeTAD for all the devices, using a mask to define the positive electrode. The architecture of the PSCs and the photographs of a typical device are reported in Fig. $\mathrm{S} 2 \mathrm{a}$ and $\mathrm{b}$, respectively (ESI $\dagger$ ). In order to evaluate the thickness of the different layers composing the devices, in addition to a mechanical profilometer, FIB was used for a rapid (few minutes) cross-sectional analysis. ${ }^{52} \mathrm{~A}$ beam of finely focused gallium ions was moved with an energy of $30 \mathrm{kV}$ and accelerated with a current of $1 \mathrm{nA}$. Ions stroke the PSC surface, milling into the surface, sputtering ionized and neutral atoms. Images were produced by scanning the ion beam at lower currents, $10 \mathrm{pA}$, to minimize sample damage (Fig. 1a and Fig. S3, ESI $\dagger$ ). An enlarged image of the cross section displayed in Fig. 1b allowed a better viewing of the thickness of the different layers. In Table S1 (ESI $\dagger$ ), the PCE of the champion devices is shown compared with other devices reported in the literature, with respect to air ambient fabrication or air storage conditions, perovskite chemical compositions, the thickness of perovskite and the architecture.

\section{Results and discussion}

\section{$J-V$ characteristics and PV parameters for pristine and stored PSCs}

Two batches of devices, completed inside the GB and outside the GB, were fabricated on the same day with $\mathrm{RH}=(30 \pm 10) \%$ at $20{ }^{\circ} \mathrm{C}$. Solar cells, after the first electrical measurement, were initially stored for $312 \mathrm{~h}$ in the dark and in a box with $(30 \pm 10) \%$ relative humidity and monitored over time.

When a decrease in the cell efficiency was recorded, the devices were placed in a low vacuum chamber $(P \sim 100 \mathrm{mbar})$ and measured over time again.

The last $J-V$ measurements were performed after $720 \mathrm{~h}$ from the fabrication day and after low vacuum exposure. The $J-V$ characteristics of the devices were always measured in humid air for both the batches of devices, constantly monitored but

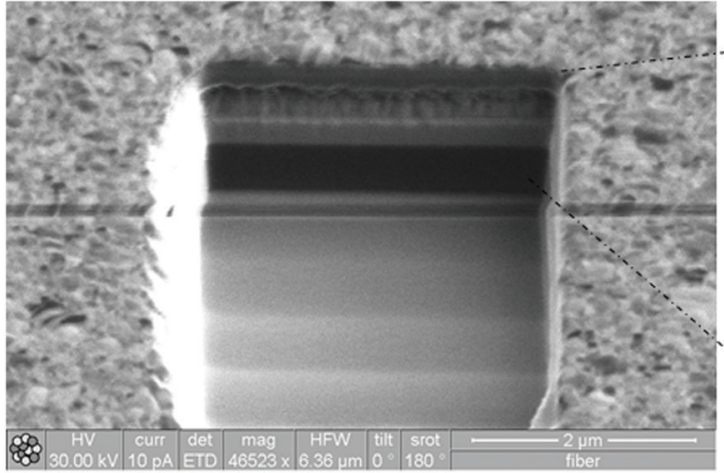

(a)

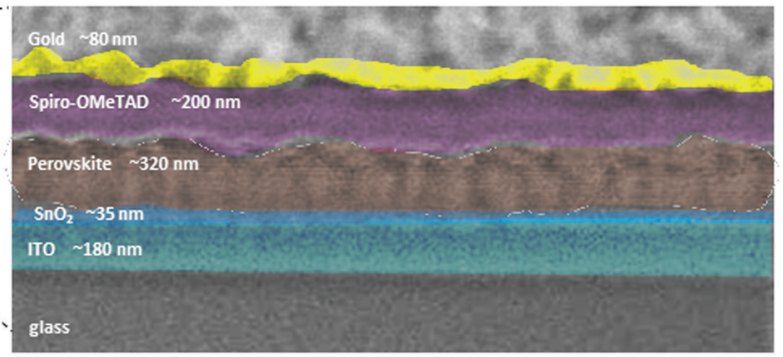

(b)

Fig. 1 (a) lon images of FIB cross section of a typical device; (b) enlarged image of the cross section and thickness of different layers measured by FIB. 

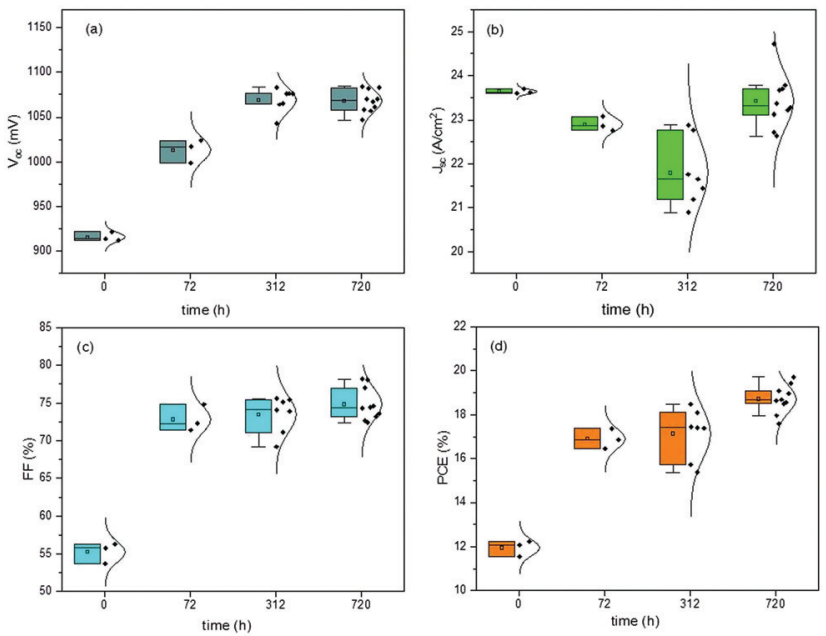

Fig. 2 Box plot charts of normal distribution of PV parameters monitored over time for devices completed outside the GB. Pristine devices were measured at time 0 , then stored in humid air for $312 \mathrm{~h}$, and measured over time at $72 \mathrm{~h}$ and $312 \mathrm{~h}$. Finally, the devices were inserted into a low vacuum chamber and measured at $720 \mathrm{~h}$ from the fabrication day.

not controlled. In Fig. 2 and 3, the box plot charts of the normal distribution of PSCs are reported for all the PV parameters. In Tables S2 and S3 (ESI $\dagger$ ), the average and champion values of each parameter measured over time for both the batches are reported. In the tables, the error values are reported as the standard deviations of three to ten devices averaged together for $V_{\mathrm{oc}}$ and $J_{\mathrm{sc}}$ data, while the error propagation was reported for FF and PCE.

The open circuit voltage $\left(V_{\text {oc }}\right)$. The $V_{\text {oc }}$ of all the devices showed a jump after the first $72 \mathrm{~h}$ in humid air (Fig. 2a and $3 \mathrm{a}$ ). After $312 \mathrm{~h}$ in humid air, the devices were inserted into a low vacuum chamber and the $V_{\text {oc }}$ increased to $1121 \mathrm{mV}$ for the champion device completed inside the glove box overcoming the $V_{\text {oc }}$ of the other batch.
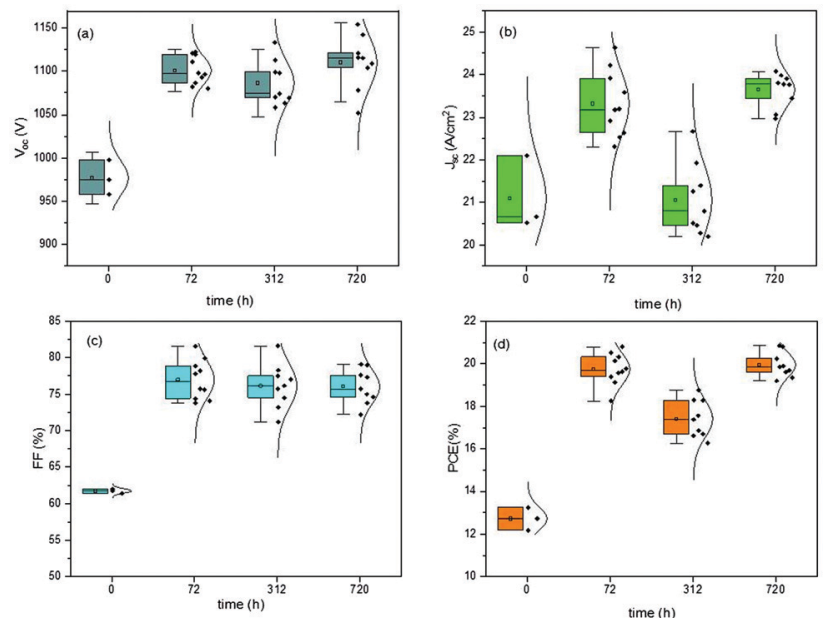

Fig. 3 Box plot charts of normal distribution of PV parameters monitored over time for devices completed inside the GB. Pristine devices were measured at time 0 , then stored in humid air for $312 \mathrm{~h}$, and measured over time at $72 \mathrm{~h}$ and $312 \mathrm{~h}$. Finally, the devices were inserted into a low vacuum chamber and measured at $720 \mathrm{~h}$ from the fabrication day.
The short circuit current density $\left(J_{\mathrm{sc}}\right)$. The $J_{\mathrm{sc}}$ of the devices completed inside the GB (Fig. 3b), after an initial strong increase in the first $72 \mathrm{~h}$ in humid air, exhibited a decrease to the initial value. A further increase in current density was recorded at $720 \mathrm{~h}$ after the fabrication day and a low vacuum cycle, showing a quite reversible behaviour. Meanwhile, the $J_{\mathrm{sc}}$ of the batch completed outside the glove box (Fig. 2b) showed the maximum value only on the first day $(t=0)$ and then started to decrease during storage in air. After $720 \mathrm{~h}$ and low vacuum storage, the $J_{\mathrm{sc}}$ reversibly increased similar to that of the previous batch (Fig. 2b).

The fill factor (FF). The FF increased in the first $72 \mathrm{~h}$ (Fig. 2c and $3 \mathrm{c}$ ) from $64.9 \%$ to $81.6 \%$ for the devices completed inside the glove box and from $56.3 \%$ to $74.8 \%$ for the other devices. After vacuum storage, the FF was quite stable for all the devices.

The power conversion efficiency (PCE). The PCE showed a great increase for the first $72 \mathrm{~h}$ (Fig. $2 \mathrm{~d}$ and $3 \mathrm{~d}$ ). After the initial rising stage $20.8 \%$ for the champion device completed inside the glove box and $17.4 \%$ for the one completed outside the glove box, with a percentage of increase of $50 \%$ and $40 \%$, respectively), the PCE continued to increase after low vacuum storage, reaching the efficiency of $20.9 \%$ for the champion device of the batch completed inside the GB, and $19.7 \%$ for the other batch. The champion device reached $20.9 \%$ independently of pristine efficiency which was about $12-13 \%$ for both the batches. The PCE, as well as FF, $V_{\mathrm{oc}}$, and $J_{\mathrm{sc}}$, improved after $72 \mathrm{~h}$ of humid air storage, and the PCE slightly decreased after $312 \mathrm{~h}$ in moisture, suggesting that competitive mechanisms are always present when moisture interacts with perovskite. Oxygen and moderate moisture have a positive effect on the photovoltaic performances, but prolonged exposure to humid air can lead to acute degradation of PSCs. ${ }^{8,46,53,54}$ The former mechanism that leads to an increase in conductivity could be attributed to the effect of water molecules (n-type dopant) ${ }^{42,43}$ and the filling of deep charge carrier traps. ${ }^{41,43,44}$ The latter mechanism could be the oxidation of Spiro-OMeTAD that increases the charge transfer at the perovskite/Spiro-OMeTAD/gold interfaces, decreasing the series resistance, $R_{\mathrm{s}}{ }^{6}{ }^{6}$ Consequently, the fill factor, dependent on $R_{\mathrm{S}}$, enhances, as well as the $V_{\mathrm{oc}}{ }^{55,56}$ A subsequent decrease in conductivity, recorded after $312 \mathrm{~h}$, was observed after prolonged exposure to humid air, which could otherwise be caused by the formation of more perovskite hydrate species. ${ }^{5}$ The exposure of devices to oxygen and moisture showed a remarkable PCE enhancement of $50 \%$ with respect to the pristine value, whereas prolonged exposure to moisture alone led to the degradation of the devices. We showed that this degradation could be avoided when the moistened devices were transferred to a low vacuum chamber, showing a further improvement of all the PV parameters. The low vacuum storage in fact should erase the effect of the hydrated species formed during the first exposure to humid air.

Furthermore, the oxygen present in the low vacuum chamber continuously improved the interface recombination between the perovskite/HTM and HTM/gold, thereby increasing the $V_{\mathrm{oc}}$. Finally, the best efficiency was obtained for the devices fabricated completely inside the nitrogen-filled glove box and after storage in humid air/low vacuum, for a total period of $720 \mathrm{~h}$ from the fabrication day. The batch of PSCs completed outside 

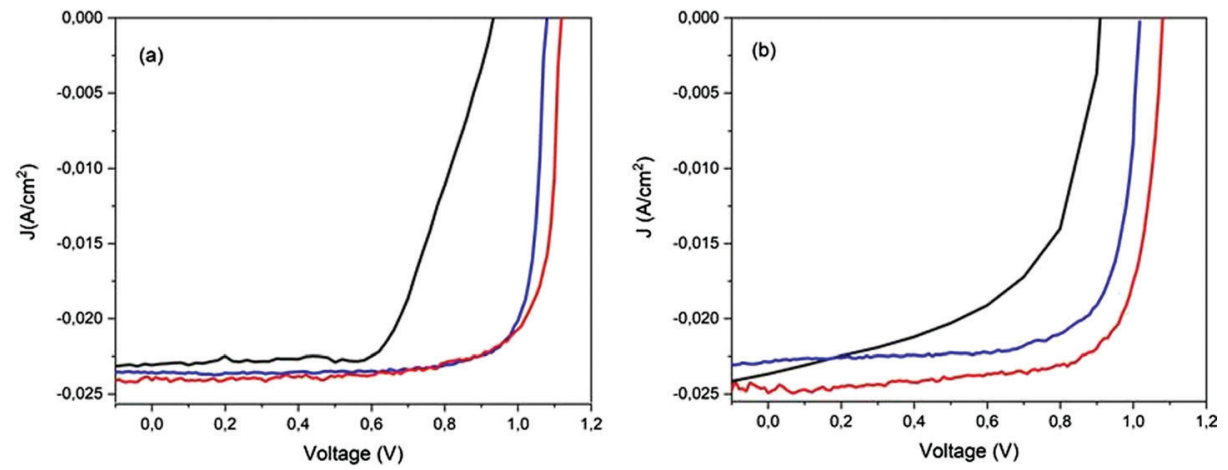

Fig. $4 \mathrm{~J}-V$ curves acquired over time, before and after storage, for champion devices: pristine (black line), at $72 \mathrm{~h}$ (blue line) and at $720 \mathrm{~h}$ (red line) from device fabrication day (a) completely inside the GB and (b) outside the GB.

the GB confirmed the results discussed previously. This set of devices, having been exposed to humid air before gold evaporation, showed a high value of pristine $J_{\mathrm{sc}}$, probably caused by the doping of water molecules incorporated into the perovskite bulk. As we formerly expected, after $72 \mathrm{~h}$ in humid air, this batch of devices completed outside the GB also exhibited a higher $V_{\mathrm{oc}}$, taking part in the oxidation of HTM, and consequently, a higher PCE. An interesting stability in performance was noted after $312 \mathrm{~h}$ in humid air and a decrease in PCE was not observed. However, also for these devices, after storage in a low vacuum chamber, PCE improvement was observed, confirming that reversible hydration was also present. ${ }^{5}$ In Fig. 4, the $J-V$ curves over the storage time of the champion perovskite devices of the two different batches completed inside (Fig. 4a) and outside the GB (Fig. 4b) monitored over time are shown.

The SEM and EDX elemental mapping of the perovskite film confirmed that moisture changed both the morphology and the bulk composition of the perovskite layer after exposure to humid air before gold evaporation (Fig. 5a, a1 and a2). More grains with smaller areas were observed when the perovskite absorber was exposed to humid air before gold evaporation (Fig. 5a and Fig. S4, ESI $\dagger$ ), while larger grain areas were observed (Fig. 5b) when the cells were completed inside the GB. This feature could at least partially explain the better performance of these PSCs. ${ }^{57,58}$ A proof that oxygen was deeply incorporated into the devices completed outside the GB, and then stored in humid air before gold evaporation, was given from EDX mapping. The presence of oxygen, among the atoms, in the devices exposed to air, before gold evaporation, evidenced the presence of probable hydrate compounds (Fig. 5a1). Moreover, after one storage cycle in low vacuum, only a small reduction of oxygen occurred (Fig. 5a2). Meanwhile, the devices completed inside the glove box, after storage in humid air and low vacuum, did not show the presence of oxygen in the structure, demonstrating a nonsignificant absorption (Fig. 5b1 and b2).

\section{Hysteresis-free behaviour of aged PSCs after storage}

Typical hysteresis graphs were shown for the pristine and stored devices after humid air and low vacuum storage (Fig. 6). The $J-V$
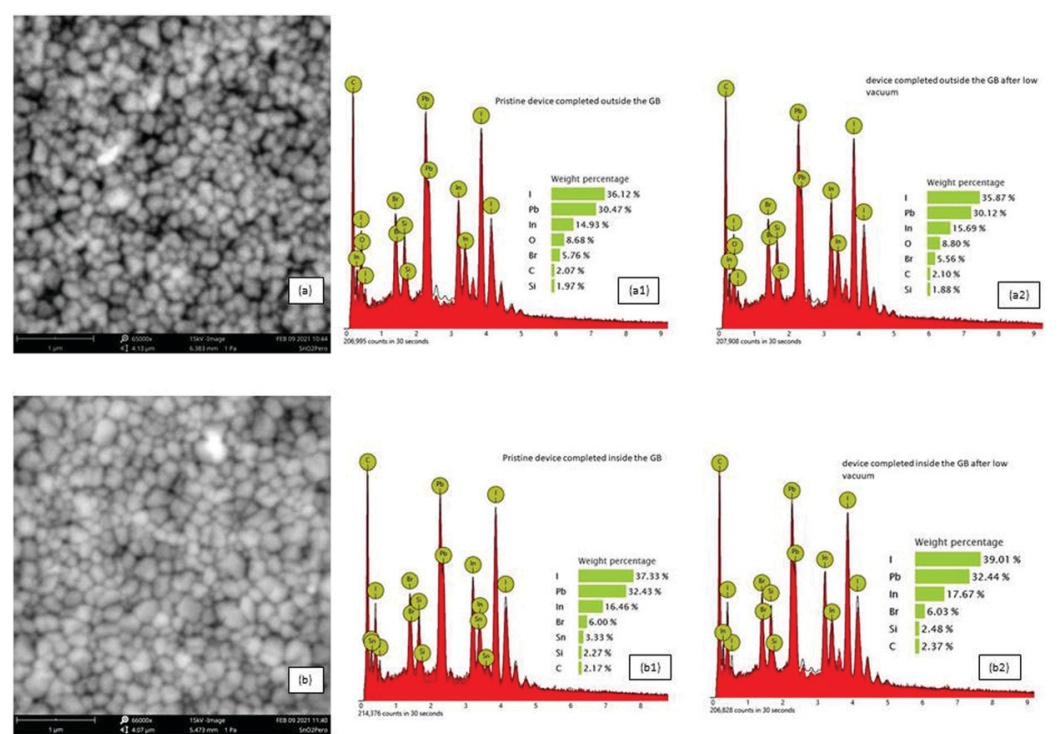

Fig. 5 SEM images of perovskite layers (a) after exposure to humid air before gold evaporation for devices completed outside the GB and (b) for devices completed inside the GB immediately after gold deposition. EDX mapping and weight percentage of elemental atoms of pristine devices completed outside the glove box (a1) and after one air/vacuum cycle (a2); pristine devices completed inside the glove box (b1) and after one air/vacuum cycle (b2). 

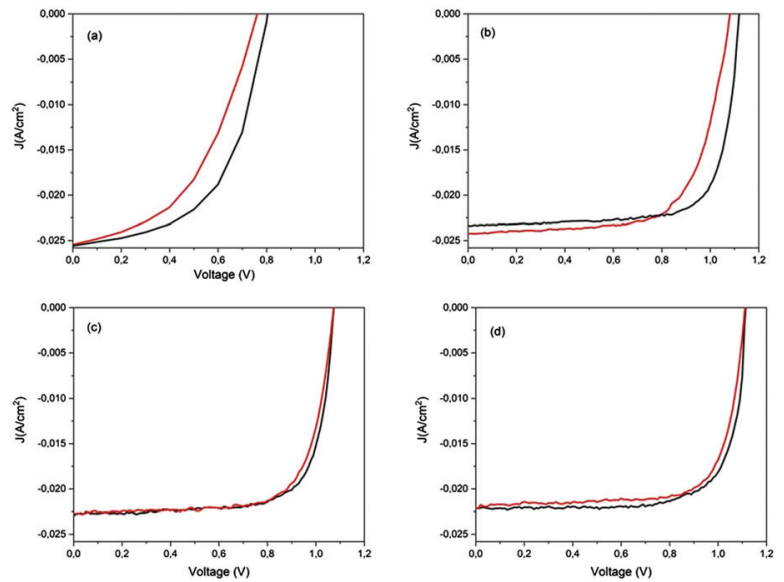

Fig. 6 Reverse (dark line) and forward (red line) scans for hysteresis behaviour: (a) pristine PSCs, (b) after $72 \mathrm{~h}$ of storage in dark and in humid air, (c) and (d) after $720 \mathrm{~h}$ from the fabrication day for devices completed outside and inside the GB, respectively.

data of the pristine devices exhibited a large discrepancy (Fig. 6a) between the reverse and forward scan directions, which decreased after $72 \mathrm{~h}$ in humid air (Fig. 6b). A hysteresis-free behaviour was observed for all the devices after $720 \mathrm{~h}$, after a cycle of humid air and low vacuum exposure (Fig. $6 \mathrm{c}$ and d). The $J-V$ hysteresis is a dynamic process which can be influenced by both pre-conditions and measurement conditions, and by material properties such as the crystallite size of the perovskite layer and the interfaces between the absorber and the electron/ hole transport materials. ${ }^{59}$

In our case, the reduction of hysteresis was dependent on the storage conditions and not on the measurement procedures because the scan rate was always the same and the applied prebias was settled to $1.2 \mathrm{~V}$ close to $V_{\mathrm{oc}}$. Humid air improves the HTM conductivity and also balances the charge transport between the electrons and holes in the ETM and HTM, thereby reducing the number of surface traps and consequently reducing the hysteresis.

\section{Dark $J-V$ and ideality factor}

The absence of hysteresis over time allowed a more in-depth evaluation of the diode characteristics with and without illumination. The dark current-voltage curves for four different devices, completed both inside and outside the GB, recorded after $720 \mathrm{~h}$ from the fabrication day, are displayed in Fig. S5 (ESI $\dagger$ ).

When the current starts to increase in a non-linear way, the trap filling process is activated. The kink point between the linear region and the non-linear one is defined using the trap-filled limit voltage $\left(V_{\mathrm{tfl}}\right)$ and it is possible to calculate the trap density, according to the space-charge-limited current (SCLC) model, using the equation: ${ }^{60}$

$$
N_{\mathrm{t}}=\frac{2 \varepsilon_{0} \varepsilon V_{\mathrm{tfl}}}{e L^{2}}
$$

where $L$ is the thickness of the perovskite layer $(\sim 320 \mathrm{~nm}), e$ is the elementary charge, $\varepsilon_{0}$ is the vacuum permittivity, and $\varepsilon$ is the dielectric constant of the perovskite film $\left(\sim 33^{61}\right)$. The $V_{\text {tfl }}$ is

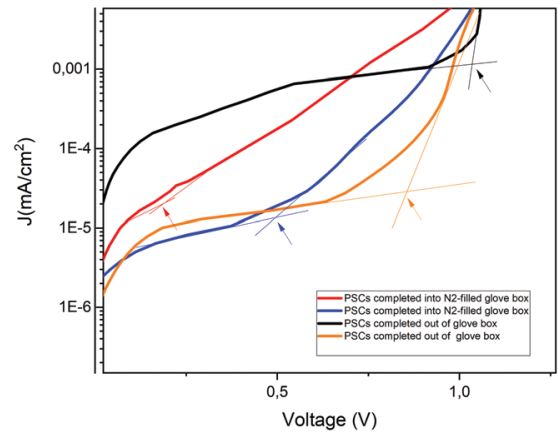

Fig. 7 Dark J-V measurements of the devices displaying the $V_{\mathrm{tfl}}$ kink point.

shown in Fig. 7 and is used to calculate the trap density, reported in Table S4 (ESI $\dagger$ ).

The devices completed inside the GB, after $720 \mathrm{~h}$, have a smaller trap density compared to the devices completed outside the GB. Then, the increase in $V_{\text {oc }}$ for the first batch during the storage time is probably due to the decrease in trap density. Probably, the incorporation of water molecules into the devices completed inside the glove box, after gold deposition and filling of deep charge carrier traps, reduces the defects and improves the conductivity of the HTM. However, water molecules incorporated into the devices completed outside the GB, before gold evaporation, leaves rather a larger trap density.

In order to investigate the recombination mechanism of the stored devices, illumination-dependent photovoltaic parameters were measured. To obtain the light-intensity dependent measurements, a set of neutral density filters was used, tuning the AM1.5 light of the solar simulator. The measurements were recorded at 1 sun $\left(100 \mathrm{~mW} \mathrm{~cm}^{-2}\right)$ and also at 0.4, 0.25, 0.16, 0.1 and 0.03 sun. The recombination was then investigated using the diode ideality factor $\left(n_{\mathrm{id}}\right)$ extracted from the current-voltage curves measured at the slope of $V_{\mathrm{oc}}$ as a function of illumination intensity. Identifying the ideality factor is a reliable way to indicate the dominant recombination mechanism of a solar cell which can be categorized into trap-assisted and bimolecular recombination. ${ }^{63-66}$ Tress et al. ${ }^{62}$ summarized that the ideality factor $\left(n_{\mathrm{id}}\right)$ of PSCs is reliably obtained by light-intensity-dependent $V_{\text {oc }}$ measurements because measurements performed using an open circuit are not affected by the parasitic series resistance. For these measurements, $n_{\text {id }}$ can be calculated using the linear fit of the $V_{\mathrm{oc}}$ as a function of $\ln \left(I_{\mathrm{ph}} / I\right)$ under relative light intensities using the equation:

$$
V_{\mathrm{oc}}=n_{\mathrm{id}} \frac{k_{\mathrm{B}} T}{e} \ln \left(\frac{I_{\mathrm{ph}}}{I}\right)
$$

where $e$ is the elementary charge, $k_{\mathrm{B}}$ is the Boltzmann constant, $T$ is the temperature, $I_{\mathrm{ph}}$ is the photocurrent under illumination and $I$ is the light intensity. Some studies reported the value of ideality factor for aged and pristine devices, suggesting that the unity value of $n$ indicates the dominance of recombination at the surface of the perovskite film, whereas $n_{\text {id }}<2$ refers to the trap-assisted Shockley-Read-Hall (SRH) recombination in the perovskite bulk. ${ }^{46,67}$ The authors found that for aged devices, 


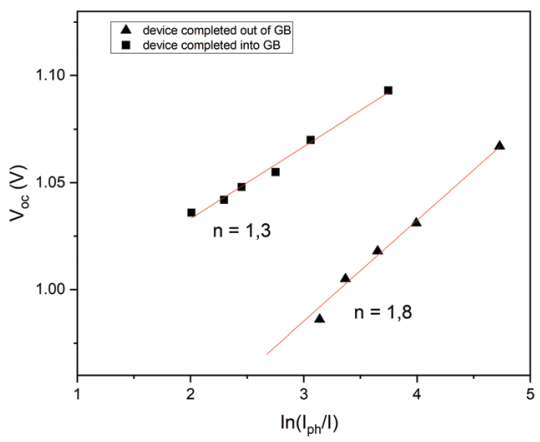

Fig. 8 Intensity-dependent $V_{\text {oc }}$ for devices completed inside and outside the GB.

the SRH recombination was dominant. For our devices, the ideality factor was calculated from the slope of $V_{\mathrm{oc}} v s . \ln \left(I_{\mathrm{ph}} / I\right)$ reported in Fig. 8. The ideality factor values were about 1.8 for the devices completed inside the GB, while about 1.3 for the devices completed outside the GB. This finding showed that the recombination mechanism changed depending on the fabrication procedure. The higher ideality factor value, calculated for the stored devices completed outside the GB, indicates the dominant existence of trap-assisted recombination, but considering the increase in $V_{\text {oc }}$, compared to that of the pristine devices, a reduction of traps or non-radiative recombination could be noted. ${ }^{46}$ Conversely, the smaller $n_{\mathrm{id}}$, calculated for the stored devices completed inside the $\mathrm{GB}$, is attributed to the band-to-band direct recombination which was confirmed from the higher values of $V_{\text {oc }}$ compared to those of all the other devices. This is reliable with the experimental results.

To gain insights into charge recombination, we also studied the variation of $J_{\mathrm{sc}}$ as a function of illumination intensity (Fig. S6, ESI $\dagger$ ). Many authors have observed a power-law dependence of $J_{\mathrm{sc}}$ upon light intensity $\left(J_{\mathrm{sc}} \sim J_{\mathrm{ph}} \sim I^{\alpha}\right.$, where $J_{\mathrm{ph}}$ is the photocurrent, $I$ is the light intensity and $\alpha$ typically ranges $\leq 1$ ). A value of $\alpha$ close to 1 indicates weak bimolecular recombination and non-space-charge limited devices, while the deviation of $\alpha$ from unity could be attributed to the bimolecular recombination, space-charge effects and variations in mobility between the holes and electrons. ${ }^{68}$ The preliminary results show the coefficient $\alpha$ to be 0.76 for the devices completed outside the GB (Fig. S6a, ESI $\dagger$ ) and 0.81 for the devices completed inside the GB (Fig. S6b, ESI $\uparrow$ ), showing sublinear dependence less marked for the second one, probably evidencing a weak bimolecular recombination. These preliminary results are calculated for the devices stored in ambient air showing that the phenomenon of charge recombination depends not only on aging but also on the manufacturing environment, i.e. if the PSCs were exposed to air before or after gold evaporation. All the aged devices were in any case hysteresisfree, and probably, the increase of performances was due to the lower migration of ions and consequently, due to the less charge recombination. The mechanism that rules these phenomena is not yet clear. It could probably be the oxygen or the water present in humid air that fills the deep charge carrier traps, as shown in this work, or it could be the lithium dopant from the HTM that could significantly dope the perovskite absorber layer through diffusion, as reported in a recent study where the authors studied this mechanism, monitoring over a three-day window, with a decrease of spontaneous non-radiative recombination from trap states, providing an increase of photovoltaic performances. ${ }^{70}$ Moreover, the improvement of PV performances, compared to fresh and aged devices, was just recently studied for all-inorganic perovskite solar cells. The authors showed that all deep defects were reduced after resting the perovskite films overnight probably due to the self-regulation mechanism, connected with the strain released over time, showing the suppression of hysteresis too. ${ }^{71}$ Immediate understanding of these mechanisms is not possible and a better insight is required to apply multiple dynamic processes under different operating conditions. Several studies have been conducted to measure the charge transfer process, such as time-of-flight secondary-ion mass spectrometry, glow discharge optical emission spectrometry, transient photovoltage decay measurements and electrochemical impedance spectroscopy. ${ }^{21,22,67,72-74}$ These analyses could give more information on charge transport in PSCs, especially when hysteresisfree devices are obtained. Further investigation is needed to study the devices stored in ambient air, adding information on charge recombination when PV parameters increase over time, by linking the results with fabrication and storage processes.

\section{Conclusions}

In summary, we studied the effects of humid air and low vacuum storage on un-encapsulated planar devices (glass/ITO/ $\mathrm{SnO}_{2} /$ triple cation perovskite/Spiro-OMeTAD/Au) fabricated completely inside a $\mathrm{N}_{2}$-filled glove box or with gold contacts deposited outside the glove box. When all the devices, independently of the fabrication procedure, are stored in humid air for $72 \mathrm{~h}$, exposure to oxygen and moisture showed an electrical conductivity enhancement and consequently, an improvement in interface charge transfer. As a result, $V_{\mathrm{oc}}$ and $\mathrm{FF}$ increased due to the faster charge extraction. The devices showed, after $312 \mathrm{~h}$ in humid air, a good stability (less than $5 \%$ change) for all the PV parameters, except for $J_{\text {sc }}$ which decreased by about $10 \%$. The subsequent storage in low vacuum preserved the PV performance of all the devices, removing partly the water molecules inside the cell and improving additionally the PV parameters. We found, for the first time, to the best of our knowledge, an impressive increase of power conversion efficiency (PCE) from $13.2 \%$ to $20.8 \%$ after $72 \mathrm{~h}$ of storage in humid air ( $\mathrm{RH}=30 \pm 10 \%$ ), and a slight increase to $20.9 \%$ after low vacuum storage and $720 \mathrm{~h}$ from the fabrication day, for PSCs fabricated completely in a nitrogen-filled glove box. Moreover, all the PV parameters increased after storage with the fill factor exceeding $80 \%$, a short circuit current density of about $24 \mathrm{~mA} \mathrm{~cm}^{-2}$ and an open circuit voltage of $1121 \mathrm{mV}$, for the champion devices. The hysteresis-free behaviour was also observed for all the devices after $720 \mathrm{~h}$. Preliminary studies on possible charge recombination mechanisms were presented which showed that the devices completed inside the glove box exhibited a weak bimolecular or band-to-band recombination which is confirmed from the higher 
values of $V_{\mathrm{oc}}$. Improvement of PV parameters of un-encapsulated pristine perovskite solar cells after storage cycles in moderate humid air and low vacuum exposure opens up a new route for following encapsulation procedures.

\section{Author contributions}

Vera La Ferrara: conceptualization, investigation, formal analysis, writing - original draft, and writing - reviewing and editing. Antonella De Maria: investigation, and writing - reviewing and editing. Gabriella Rametta: investigation, and writing - reviewing and editing. Paola Delli Veneri: project administration, and writing - reviewing and editing.

\section{Conflicts of interest}

There are no conflicts to declare.

\section{Acknowledgements}

The authors would like to thank Dr Enrico La Manna, Dr Emanuele Calabrò and Prof. Aldo Di Carlo (Centre for Hybrid and Organic Solar Energy (CHOSE), Rome, Italy), Dr Gennaro Sannino (ENEA and University “Federico II” Naples, Italy) and Dr Annalisa Bruno (Energy Research Institute@NTU, Singapore and ENEA, Italy) for their preliminary insights into tin oxide and triple cation perovskite layers, Dr Luca Serenelli (ENEA, Italy) for software for electrical characterization, and Antonio Romano and Antonio Citarella (ENEA, Italy) for maintenance of measurement equipment and holder-mask manufacturing. This work was supported by the Italian Ministry of Economic Development in the Framework of the Operating Agreement with ENEA for Research on the Electric System.

\section{References}

1 M. Liu, M. B. Johnston and H. Snaith, Nature, 2013, 501, 395-398.

2 H. S. Kim, I. Mora-Sero, V. Gonzalez-Pedro, F. Fabregatsantiago, E. J. Juarez-Perez, N. G. Park and J. Bisquert, Nat. Commun., 2013, 4, 2242.

3 J. J. Yoo, G. Seo, M. R. Chua, T. G. Park, Y. Lu, F. Rotermund, Y. Y. Kim, C. S. Moon, N. J. Jeon, J. P. Correa-Baena, V. Bulovic, S. S. Shin, M. G. Bawendi and J. Seo, Nature, 2021, 590, 587-593.

4 Best Research-Cell Efficiency Chart. https:/www.nrel.gov/ pv/cell-efficiency.html (accessed 25 March 2021).

5 Z. Song, A. Abate, S. C. Watthage, G. K. Liyanage, A. B. Phillips, U. Steiner, M. Graetzel and M. J. Heben, Adv. Energy Mater., 2016, 6, 1600846.

6 Z. Hawash, L. K. Ono and Y. Qi, Adv. Mater. Interfaces, 2016, 3, 1600117.

7 M. F. M. Noh, N. A. Arzaee, I. N. N. Mumthas, N. A. Mohamed, S. N. F. M. Nasir, J. Safaei, A. R. B. M. Yusoff, M. K. Nazeeruddin and M. A. M. Teridi, J. Mater. Chem. A, 2020, 8, 10481-10518.
8 M. A. Haque, A. Syed, F. H. Akhtar, R. Shevate, S. Singh, K. V. Peinemann, D. Baran and T. Wu, ACS Appl. Mater. Interfaces, 2019, 11, 29821-29829.

9 I. Mesquita, L. Andrade and A. Mendes, Sol. Energy, 2020, 199, 474-483.

10 I. Mesquita, L. Andrade and A. Mendes, ChemSusChem, 2019, 12, 2186-2194.

11 E. Ugur, E. Alarousu, J. I. Khan, A. Vlk, E. Aydin, M. De Bastiani, A. H. Balawi, S. P. Gonzalez Lopez, M. Ledinský, S. De Wolf and F. Laquai, Sol. RRL, 2020, 4, 2000382.

12 H. A. Dewi, H. Wang, J. Li, M. Thway, R. Sridharan, R. Stangl, F. Lin, A. G. Aberle, N. Mathews, A. Bruno and S. Mhaisalkar, ACS Appl. Mater. Interfaces, 2019, 11, 34178-34187.

13 A. Al-Ashouri, E. Köhnen, B. Li, A. Magomedov, H. Hempel, P. Caprioglio, J. A. Márquez, A. B. M. Vilches, E. Kasparavicius, J. A. Smith, N. Phung, D. Menzel, M. Grischek, L. Kegelmann, D. Skroblin, C. Gollwitzer, T. Malinauskas, M. Jošt, G. Matič, B. Rech, R. Schlatmann, M. Topič, L. Korte, A. Abate, B. Stannowski, D. Neher, M. Stolterfoht, T. Unold, V. Getautis and S. Albrecht, Science, 2020, 370, 1300-1309.

14 G. Nogay, F. Sahli, J. Werner, R. Monnard, M. Boccard, M. Despeisse, F.-J. Haug, Q. Jeangros, A. Ingenito and C. Ballif, ACS Energy Lett., 2019, 4, 844-845.

15 E. Lamanna, F. Matteocci, E. Calabrò, L. Serenelli, E. Salza, L. Martini, F. Menchini, M. Izzi, A. Agresti, S. Pescetelli, S. Bellani, A. Easù Del Rìo Castillo, F. Bonaccorso, M. Tucci and A. Di Carlo, Joule, 2020, 4, 865-881.

16 Y. Zhang and N. G. Park, J. Mater. Chem. A, 2020, 8, 17420-17428. 17 E. López-Fraguas, B. Arredondo, C. Vega-Colado, G. del Pozo, M. Najafi, D. Martín-Martín, Y. Galagan, J. M. Sánchez-Pena, R. Vergaz and B. Romero, Org. Electron., 2019, 73, 292-298.

18 J. Choi, S. Song, M. T. Hörantner, H. J. Snaith and T. Park, ACS Nano, 2016, 10, 6029-6036.

19 F. Giordano, A. Abate, J. P. C. Baena, M. Saliba, T. Matsui, S. H. Im, S. M. Zakeeruddin, M. K. Nazeeruddin, A. Hagfeldt and M. Graetzel, Nat. Commun., 2016, 7, 10379.

20 B. Conings, L. Baeten, T. Jacobs, R. Dera, J. D’Haen, J. Manca and H. G. Boyen, APL Mater., 2014, 2, 081505.

21 B. Wang, M. Zhang, X. Cui, Z. Wang, M. Rager, Y. Yang, Z. Zou, Z. L. Wang and Z. Lin, Angew. Chem., Int. Ed., 2020, 59, 1611.

22 X. Meng, X. Cui, M. Rager, S. Zhang, Z. Wang, J. Yu, Y. W. Harn, Z. Kang, B. K. Wagner, Y. Liu, C. Yu, J. Qiu and Z. Lin, Nano Energy, 2018, 52, 123.

23 Q. Jiang, L. Zhang, H. Wang, X. Yang, J. Meng, H. Liu, Z. Yin, J. Wu, X. Zhang and J. You, Nat. Energy, 2017, 2, 16177.

24 S. Albrecht, M. Saliba, J. P. Correa Baena, F. Lang, L. Kegelmann, M. Mews, L. Steier, A. Abate, J. Rappich, L. Korte, R. Schlatmann, M. K. Nazeeruddin, A. Hagfeldt, M. Grätzel and B. Rech, Science, 2016, 9(1), 81-88, DOI: 10.1039/C5EE02965A.

25 L. V. Mercaldo, E. Bobeico, A. De Maria, M. Della Noce, M. Ferrara, V. La Ferrara, L. Lancellotti, G. Rametta, G. V. Sannino, I. Usatii and P. Delli Veneri, Proceedings in EU PVSEC 2021, 6-10 September 2021, submitted.

26 T. S. Sherkar, C. Momblona, L. Gil-Escrig, J. Ávila, M. Sessolo, H. J. Bolink and L. J. A. Koster, ACS Energy Lett., 2017, 2, 1214-1222. 
27 C. M. Wolff, P. Caprioglio, M. Stolterfoht and D. Neher, Adv. Mater., 2019, 31, 1902762.

28 K. Kobbekaduwa, S. Shrestha, P. Adhikari, E. Liu, L. Coleman, J. Zhang, Y. Shi, Y. Zhou, Y. Bekenstein, F. Yan, A. M. Rao, H. Tsai, M. C. Bead, W. Nie and J. Gao, Nat. Commun., 2021, 12, 16362021.

29 L. X. Shi, Z. S. Wang, Z. Huang, W. E. I. Sha, H. Wang and Z. Zhou, AIP Adv., 2018, 8, 025312.

30 P. Zhao, B. J. Kim and H. S. Jung, Mater. Today Energy, 2018, 7, 267-286.

31 X. Wu, L. Zhang, Z. Xu, S. Olthof, X. Ren, Y. Liu, D. Yang, F. Gao and S. (Frank) Liu, J. Mater. Chem. A, 2020, 8, 8313-8322.

32 A. Abate, M. Saliba, D. J. Hollm, S. D. Stranks, K. Wojciechowski, R. Avolio, G. Grancini, A. Petrozza and H. J. Snaith, Nano Lett., 2014, 14, 3247-3254.

33 C. M. Wolff, L. Canil, C. Rehermann, N. N. Linh, F. Zu, M. Ralaiarisoa, P. Caprioglio, L. Fiedler, M. Stolterfoht, S. Kogikoski Jr, I. Bald, N. Koch, E. L. Unger, T. Dittrich, A. Abate and D. Neher, ACS Nano, 2020, 14, 1445-1456.

34 M. Moriya, D. Hirotani, T. Ohta, Y. Ogomi, Q. Shen, T. S. Ripolles, K. Yoshino, T. Toyoda, T. Minemoto and S. Hayase, ChemSusChem, 2016, 9, 2634-2639.

35 T. J. Jacobsson, J. P. Correa-Baena, E. H. Anaraki, B. Philippe, S. D. Stranks, M. E. F. Bouduban, W. Tress, K. Schenk, J. Teuscher, J. E. Moser, H. Rensmo and A. Hagfeldt, J. Am. Chem. Soc., 2016, 138, 10331-10343.

36 F. Liu, Q. Dong, M. K. Wong, A. B. Djurišić, A. Ng, Z. Ren, Q. Shen, C. Surya, W. K. Chan, J. Wang, A. M. C. Ng, C. Liao, H. Li, K. Shih, C. Wei, H. Su and J. Dai, Adv. Energy Mater., 2016, 6, 1502206.

37 Y. X. Tian, A. Merdasa, E. Unger, M. Abdellah, K. Zheng, S. McKibbin, A. Mikkelsen, T. Pullerits, A. Yartsev, V. Sundstrom and I. G. Scheblykin, J. Phys. Chem. Lett., 2015, 6, 4171-4177.

38 A. Ng, Z. W. Ren, Q. Shen, S. H. Cheung, H. C. Gokkaya, S. K. So, A. B. Djurisic, Y. Y. Wan, X. J. Wu and C. Surya, ACS Appl. Mater. Interfaces, 2016, 8, 32805-32814.

39 Z. W. Ren, A. Ng, Q. Shen, H. C. Gokkaya, J. Wang, L. Yang, W. K. Yiu, G. Bai, A. B. Djurisic, W. W. F. Leung, J. H. Hao, W. K. Chan and C. Surya, Sci. Rep., 2014, 4, 6752.

40 W. J. Yin, H. Chen, T. Shi, S. H. Wei and Y. Yan, Adv. Electron. Mater., 2015, 1, 1500044.

41 J. Huang, S. Tan, P. D. Lund and H. Zhou, Energy Environ. Sci., 2017, 10, 2284-2311.

42 Z. Song, N. Shrestha, S. C. Watthage, G. K. Liyanage, Z. S. Almutawah, R. H. Ahangharnejhad, A. B. Phillips, R. J. Ellingson and M. J. Heben, J. Phys. Chem. Lett., 2018, 9, 6312-6320.

43 Y. Li, X. Xu, C. Wang, C. Wang, F. Xie, J. J. Yang and Y. Gao, J. Phys. Chem. C, 2015, 119, 23996-24002.

44 R. Long, W. Fang and O. V. Prezhdo, J. Phys. Chem. Lett., 2016, 7, 3215-3222.

45 X. Wang, H. Sarvari, H. Dang, Z. Chen and V. Singh, Optik, 2017, 150, 111-116.

46 Y. Cho, H. Do Kim, J. Zheng, J. Bing, Y. Li, M. Zhang, M. A. Green, A. Wakamiya, S. Huang, H. Ohkita and A. W. Y. Ho-Baillie, ACS Energy Lett., 2021, 6, 925-933.
47 F. Matteocci, L. Cina, E. Lamanna, S. Cacovich, G. Divitini, P. A. Midgley, C. Ducati and A. Di Carlo, Nano Energy, 2016, 30, 162-172.

48 F. Corsini and G. Griffini, J. Phys. Energy, 2020, 2, 031002.

49 Y. Lv, H. Zhang, R. Liu, Y. Sun and W. Huang, ACS Appl. Mater. Interfaces, 2020, 12, 27277-27285.

50 M. Saliba, T. Matsui, J. Y. Seo, K. Domanski, J. P. CorreaBaena, M. K. Nazeeruddin, S. M. Zakeeruddin, W. Tress, A. Abate, A. Hagfeldtd and M. Grätzel, Energy Environ. Sci., 2016, 9, 1989-1997.

51 M. Saliba, J.-P. Correa-Baena, C. M. Wolff, M. Stolterfoht, N. Phung, S. Albrecht, D. Neher and A. Abate, Chem. Mater., 2018, 30, 4193-4201.

52 E. Enz, V. La Ferrara and G. Scalia, ACS Nano, 2013, 7, 6627-6635.

53 Q. Wang, B. Chen, Y. Liu, Y. Deng, Y. Bai, Q. Dong and J. Huang, Energy Environ. Sci., 2017, 10, 516-522.

54 G. E. Eperon, S. N. Habisreutinger, T. Leijtens, B. J. Bruijnaers, J. J. van Franeker, D. W. deQuilettes, S. Pathak, R. J. Sutton, G. Grancini, D. S. Ginger, R. A. J. Janssen, A. Petrozza and H. J. Snaith, ACS Nano, 2015, 9, 9380-9393.

55 A. Abate, T. Leijtens, S. Pathak, J. Teuscher, R. Avolio, M. E. Errico, J. Kirkpatrik, J. M. Ball, P. Docampo, I. McPhersonc and H. J. Snaith, Phys. Chem. Chem. Phys., 2013, 15, 2572-2579.

56 P. Caprioglio, M. Stolterfoht, C. M. Wolff, T. Unold, B. Rech, S. Albrecht and D. Neher, Adv. Energy Mater., 2019, 9, 1901631.

57 X. Guo, C. McCleese, W. Gao, M. Wang, L. Sang and C. Burda, Mater. Renewable Sustainable Energy, 2016, 5, 17.

58 S. Moghadamzadeh, I. M. Hossain, M. Jakoby, B. A. Nejand, D. Rueda-Delgado, J. A. Schwenzer, S. Gharibzadeh, T. Abzieher, M. R. Khan, A. A. Haghighirad, I. A. Howard, B. S. Richards, U. Lemmer and U. W. Paetzold, J. Mater. Chem. A, 2020, 8, 670-682.

59 G. A. Nemnes, C. Besleaga, A. G. Tomulescu, L. N. Leonat, V. Stancu, M. Florea, A. Manolescu and I. Pintilie, J. Mater. Chem. C, 2019, 7, 5267-5274.

60 R. H. Bube, J. Appl. Phys., 1962, 33, 1733-1737.

61 R. A. Awni, Z. Song, C. Chen, C. Li, C. Wang, M. A. Razooqi, L. Chen, X. Wang, R. J. Ellingson, J. V. Li and Y. Yan, Joule, 2020, 4, 644-657.

62 W. Tress, M. Yavari, K. Domanski, P. Yadav, B. Niesen, J. P. Correa Baena, A. Hagfeldt and M. Graetzel, Energy Environ. Sci., 2018, 11, 151-165.

63 P. Calado, D. Burkitt, J. Yao, J. Troughton, T. M. Watson, M. J. Carnie, A. M. Telford, B. C. O'Regan, J. Nelson and P. R. F. Barnes, Phys. Rev. Appl., 2019, 11, 044005.

64 J. P. Correa-Baena, S. H. Turren-Cruz, W. Tress, A. Hagfeldt, C. Aranda, L. Shooshtari, J. Bisquert and A. Guerrero, ACS Energy Lett., 2017, 2, 681-688.

65 O. J. Sandberg, A. Sundqvist, M. Nyman and R. Österbacka, Phys. Rev. Appl., 2016, 5, 044005.

66 L. J. A. Koster, V. D. Mihailetchi, H. Xie and P. W. M. Blom, Appl. Phys. Lett., 2005, 87, 203502. 
67 A. Mahapatra, N. Parikh, P. Kumar, M. Kumar, D. Prochowicz, A. Kalam, M. M. Tavakoli and P. Yadav, Molecules, 2020, 25, 2299.

68 L. J. Koster, V. D. Mihailetchi, H. Xie and P. W. Blom, Appl. Phys. Lett., 2005, 87, 203502.

69 Q. Jiang, L. Zhang, H. Wang, X. Yang, J. Meng, H. Liu, Z. Yin, J. Wu, X. Zhang and J. You, Nat. Energy, 2017, 2, 16177.

70 C. Xiao, F. Zhang, Z. Li, S. P. Harvey, X. Chen, K. Wang, C.-S. Jiang, K. Zhu and M. Al-Jassim, Matter, 2020, 2, 261-272.

71 Z. Yao, Z. Xu, W. Zhao, J. Zhang, H. Bian, Y. Fang, Y. Yang and S. (Frank) Liu, Adv. Energy Mater., 2021, 11, 2100403.
72 Z. Li, C. Xiao, Y. Yang, S. P. Harvey, D. Kim, J. A. Christians, M. Yang, P. Schulz, S. U. Nanayakkara, C. S. Jiang, J. M. Luther, J. J. Berry, M. C. Beard, M. M. Al-Jassim and K. Zhu, Energy Environ. Sci., 2017, 10, 1234-1242.

73 H. Lee, S. Gaiaschi, P. Chapon, A. Marronnier, H. Lee, J.-C. Vanel, D. Tondelier, J.-E. Boureé, Y. Bonnassieux and B. Geffroy, ACS Energy Lett., 2017, 2, 943-949.

74 A. Pockett and M. J. Carnie, ACS Energy Lett., 2017, 2(7), 1683-1689.

75 Q. Jiang, Z. Chu, P. Wang, X. Yang, H. Liu, Y. Wang, Z. Yin, J. Wu, X. Zhang and J. You, Adv. Mater., 2017, 29, 1703852. 